Session 3213

\title{
Process Simulation Failure as a Learning Tool
}

\author{
David L. Silverstein \\ University of Kentucky
}

\begin{abstract}
Chemical process simulators have become ubiquitous in chemical engineering education. Students frequently view them as a black box of wonder that will make their engineering life much easier, when in fact the simulator may actually more closely resemble Pandora's Box. When given a choice amongst an analytical solution to model equations, a numerical solution to model equations, or a simulator solution, students often trust the simulator results over their model, not realizing the simulator uses the same (or possibly an inappropriate) model. This paper discusses an approach of "learning through failure", where students develop simulations for systems that produce results not matching reality. The goal is to make students aware of the need to critically validate any results obtained from a process simulator.
\end{abstract}

\section{Introduction}

Process simulation has become a core element of chemical engineering education. Recent surveys have indicated that simulators are used in most chemical engineering curricula, with an increasing use outside the capstone design course. Equilibrium staged separations, process control, and thermodynamics courses are the three most common settings for incorporating simulation into the curriculum outside the capstone design sequence. ${ }^{1}$

The increased use of process simulation has coincided with an increased dependency on computers in the lives of students. Students have grown accustomed to using computers for entertainment as well as engineering, and tend to trust software to give them accurate answers. With process simulators, this attitude is potentially dangerous. The adage "garbage in, garbage out" applies to process simulation, a fact that may be lost as fewer programs require computer programming as part of the core curriculum. ${ }^{1}$ For the purposes of this paper, process simulation failure is defined as simulations that run as expected, but yield results inconsistent with the processes they are intended to simulate.

\section{Motivation}

One of the topics covered during the Spring 2001 and Spring 2002 offerings of a course in Process Modeling at the University of Kentucky (UK) extended campus in Paducah was the need to validate computer generated results through various methods. As part of this discussion, the role of numerical methods in process simulation was covered along 
with the error inherent in numeric calculations. On the final exam, a question similar to this one was posed:

The model for a reactor system yields the following predictions for a reactor scheme, depending on the solution method used:

Process simulator solution using [process simulator], conversion $=0.72$

Numerical solution using [math package], conversion $=0.85$

Analytical solution by hand, conversion $=0.97$

Assuming the same physical property models are used for each, which of these results should most likely be accepted as the correct answer? Why?

Of the seven students in the course, only one chose the correct answer, the analytical solution. Most chose the process simulator solution over the other options.

There appears to be a bias on the part of the students towards trusting expensive simulator packages without considering how simulators work, what models are used, what assumptions are made, or potential sources of numerical error. To begin the process of correcting this bias, examples from the literature were sought to demonstrate situations in which process simulation fails while still providing answers which appear reasonable to the inexperienced practitioner.

\section{Goals and Objectives}

Five issues were identified to be addressed in courses leading to the process modeling course:

1. The need to validate simulation results

2. Stability of numerical methods

3. Importance of valid property models

4. Understanding of how simulators work

5. Importance of sensitivity analysis

Some of these issues are already addressed in courses, but may be in need of greater emphasis. Additionally, in response to feedback from recent graduates and employers, additional integration of computing into the curriculum is taking place by using process simulators to a limited degree in courses targeted at sophomores and freshmen. The methods and examples suggested in this paper will be mapped to these goals but placing the goal numbers in parenthesis, e.g., (Goal 1). These goals have not yet been adopted by the program faculty as a whole, so to date the efforts have involved limited course sections. Assessment of effectiveness of these approaches is also limited due to nonideality of instructor assignments and small number of students (ranges from 2-10 per class). 


\section{Course Integration and Problem Examples}

There are some courses where it makes sense to use simulators. Any design course, such as equilibrium staged separations or reactor design, would likely benefit from a project involving a process simulator. Additionally, the thermodynamics course would also benefit for a fundamental reason. In Figure 1, the list of property models employed by a popular process simulator is shown. Even though a brief explanation of each model is given in the status bar, and greater detail is available in the help files for the simulator, it seems instinctive that students would benefit most from examining the choices available while the names of the procedures, theories, methods, and equations hold meaning from recent exposure in the course. The same logic applies to learning the process for reaction modeling in the reactor design course and for choosing a shortcut method for distillation column simulation in the staged separations course. Students would benefit most from use of process simulation when the models, concepts, theories, and procedures used by the simulator are being taught in a course. (Goal 3)

Simulators were introduced into the four semester-hour thermodynamics course at UK in 2002 with objectives of teaching students to choose appropriate thermodynamics models and to validate property models before accepting simulation results. Students worked through two processes in a single-session workshop format lasting about 90 minutes. This was the second exposure students had to a commercial simulator, the first coming through a workshop the previous semester (the stoichiometry course) focused on creating flow sheets in Aspen Plus. The first was a simple flash process for which they were required to generate T-xy diagrams and compare to data obtained from the literature. The second was a distillation process involving an azeotrope. They experimented with several models until they found an appropriate model which accounted for the azeotrope. Several were surprised that what they had perceived as "fail-safe" models did not work for the ethanol/ water system. Figure 2 shows the T-xy diagram students identified as being valid using NRTL. Additionally, a LLE problem was demonstrated, where students were reminded that some activity coefficient models were incapable of accounting for two liquid phases. (Goals 3, 4)

Process modeling is a three-hour junior-level course at UK which ties numerical methods to chemical engineering problems through the model development process. The course follows a design course in equilibrium-staged separations and runs concurrently with a course in heat and mass transfer. Simulators have been used to enable quick comparisons between different modeling methods, as well as to demonstrate situations where numeric instabilities arise. Additional approaches are being integrated into the current offering of the course, including emphasis on comparing errors associated with different methods. For example, a problem requiring determination of parameters associated with a first order differential equation was solved using several methods. ${ }^{2}$ The primary methods of comparison involved numerical differentiation of experimental data followed by regression, and numerical integration. Different numerical methods for differentiation and integration were used and the results compared. Students were asked to determine 
which value was most likely valid, and then justify their answer. This required students to consider the effects of data spacing, approximation order of error, and re-emphasized the need to plot data and use the visual representation of data before making judgments on the validity of numerical calculations. (Goals 1,2 )

Another interesting problem that has been used (by Professor Dibakar Bhattacharyya in the Chemical and Materials Engineering (CME) department at UK) in this course comes from the textbook by Cutlip and Shacham. ${ }^{3}$ Problem 1.5 in this text is a series of three distillation columns, where Column 2 takes its feed from the overhead of Column 1, and Column 3 takes the bottoms from Column 1 as its feed. There are four components in the separation train, and all feed and product streams have defined compositions. The feed to Column 1 is also specified.

When solving this problem as published, the determinant of the coefficient matrix of the system of material balances approaches zero (Figure 3). The importance of this sensitivity is apparent when the composition of one of the product streams is altered by $1 \%$. As shown in Figure 4, this change results in unrealizable compositions and flow rates for some streams. Simulation in a popular process simulator, however, results in a realizable solution. Students chose to report their process simulator result instead of the analytical and computer-generated numerical results, citing how the simulator was "smarter" than they were. This example of process simulator "failure" provides an opportunity to re-emphasize the importance of critically examining computer output and validating it with experimental data and hand calculations. It also serves to emphasize the need to use sensitivity analysis and the role it plays in determining how much should be invested in refining input data into a model. (Goals 2, 4, 5)

The next addition to the process modeling course will be a module on process simulation, based on a chapter from Felder and Rousseau's textbook. ${ }^{4}$ This module will instruct students on how commercial simulators handle the types of models they have spent the semester developing, and will provide additional opportunities to see how numerical methods can fail yet still provide answers. (Goal 4). The latest version of the stoichiometry textbook by Himmelblau and Riggs also provides a similar chapter. ${ }^{5}$ Lewin et. al. has published a recently revised multimedia guide to process simulators as well. ${ }^{6}$

\section{Where to Go From Here}

The literature has a good number of articles which can lead to student exercises to reinforce the need to validate process simulation results. Wankat has published an article ${ }^{7}$ and column ${ }^{8}$ recently which describe pedagogically sound approaches to using simulators. Savelski and Hesketh have published a detailed set of simulator problems they have used in courses in reaction engineering and process design, ${ }^{9}$ emphasizing the need for "reality checks". 
To develop new problems which fail, the literature provides some useful starting points. Some recent articles include Kister's historical list of real-world scenarios (primarily separations) where simulations failed to predict what actually occurred, often with disastrous results. ${ }^{10}$ Chemical Engineering Progress published a series by Agarrwal emphasizing the need to validate simulators, including some examples of failure. ${ }^{11}$ Le's article also emphasizes the need to critically evaluate simulation results. ${ }^{12}$ Tanzio's paper focuses on validation methods. ${ }^{13}$ Sadeq has also published on this subject. ${ }^{14}$ Carnahan and Clough have provided a useful collection of spreadsheet based simulators which provide an excellent resource from which to develop problems which fail. ${ }^{15}$

\section{Summary}

Process simulation is a key element of modern chemical engineering education and practice. The need to critically consider simulation results must be emphasized in chemical engineering curricula. Some approaches to integrating instruction in simulation while emphasizing the need to validate are presented. Five specific goals for student learning are proposed, with suggestions for course integration and specific examples of problems intended to address them: validation of simulation results, stability of numerical methods, importance of valid property models, understanding of how simulators work, and importance of sensitivity analysis. Additional resources for developing modules to teach through simulation failure are provided through a brief survey of recent literature. 


\section{Bibliography}

${ }^{1}$ Dahm, Kevin D., Hesketh, Robert P., Savelski, Mariano J., "Is Process Simulation Used Effectively in ChE Courses?” Chem. Eng. Ed., Summer 2002, pp. 192-203

${ }^{2}$ Chapra, Steven C., Canale, Raymond P., "Problem 24.36" in Numerical Methods for Engineers, Fourth Edition, McGraw Hill, St. Louis, 2002, p. 663.

${ }^{3}$ Cutlip, Maciael B., Shacham, Mordechai, Problem Solving in Chemical Engineering with Numerical Methods, Prentice Hall, NY, 1999.

${ }^{4}$ Felder, Richard M., Rousseau, Ronald R., "Computer-Aided Balance Calculations” in Elementary Principles of Chemical Processes, Third Edition, Wiley, NY, 2001.

${ }^{5}$ Himmelblau, David M., Riggs, James B., "Solving Material and Energy Balances Using Process Simulators (Flowsheeting Codes)" in Basic Principles and Calculations in Chemical Engineering, Seventh Edition, Prentice Hall, NY, 2004.

${ }^{6}$ Lewin, Daniel R, et.al., Using Process Simulators in Chemial Engineering: A Multimedia Guide for the Core Curriculum, Version 2.0 for Windows, Wiley, NY, 2003.

${ }^{7}$ Wankat, Phillip C., "Integrating the Use of Commercial Simulators into Lecture Courses", JEE, January 2002, pp 19-23

${ }^{8}$ Wankat, Philip C., Oreovicz, Frank, “Teaching: Simulators to Stimulate Students”, Prism, January 2004, p. 45 .

${ }^{9}$ Savelski, Mariano J., Hesketh, Robert P., "Issues Encountered with Students Using Process Simulators", Proceedings of the 2003 American Society for Engineering Education Annual Conference and Exposition.

${ }^{10}$ Kister, Henry K., “Can We Believe the Simulation Results?”, CEP, October 2002, pp. 52-58.

${ }^{11}$ Agarrwal, R. et.al., "Uncovering the Realities of Simulation”, Part I and Part II, CEP, May 2001 and June 2001 .

${ }^{12}$ Le, N.D., et.al., "Doublecheck Your Process Simulations," CEP, May 2000, p.51.

${ }^{13}$ Tanzio, Michael, "Validate Your Engineering Software”, CEP, July 2001, 64-73.

${ }^{14}$ Sadeq, J., et al., "Anomalous Results from Process Simulators," Chem. Eng. Education (Winter 1997).

${ }^{15}$ Clough, D. and Carnahan, B. Workshop 18: Integrating Computing across theCurriculum via Spreadsheets, ASEE Chemical Engineering Post Summer SchoolSummer 2002, Boulder, Colorado.

\section{DAVID L. SILVERSTEIN}

David L. Silverstein is currently an Assistant Professor of Chemical and Materials Engineering at the University of Kentucky College of Engineering Extended Campus Programs in Paducah. He received his B.S.Ch.E. from the University of Alabama in Tuscaloosa, Alabama; his M.S. and Ph.D in Chemical Engineering from Vanderbilt University in Nashville, Tennessee; and has been a registered P.E. since 2002. He has over twenty years experience in microcomputer programming, most recently in development of a prototype automatic custom videotape editing and production device. In addition to teaching and research in interfacial phenomena, Dr. Silverstein is developing a computer framework for applying learning styles to a multimedia computer-based supplement to engineering courses. 


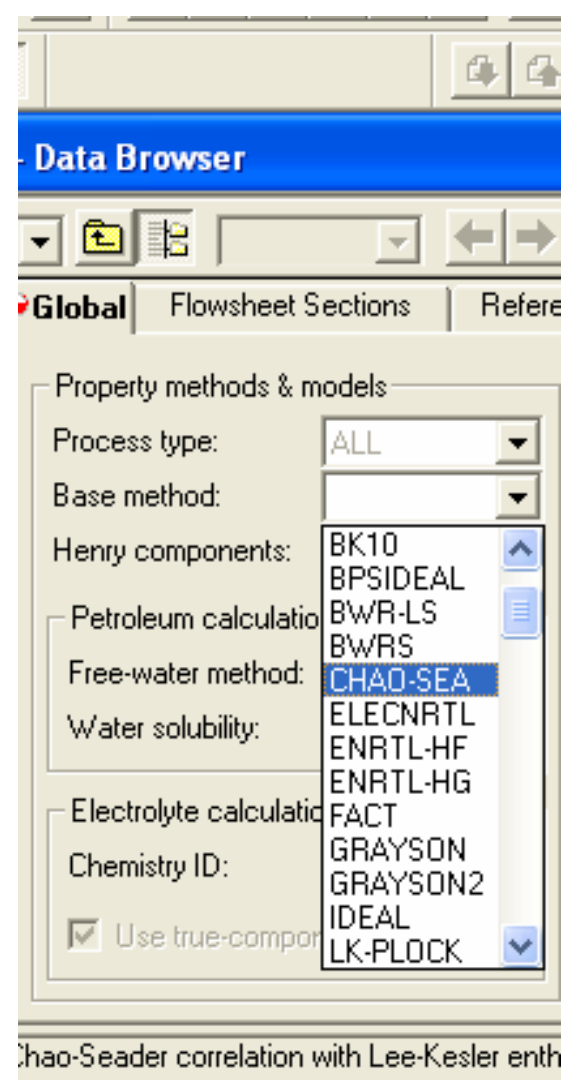

Figure 1. A selection of property models available within a popular process simulator. 


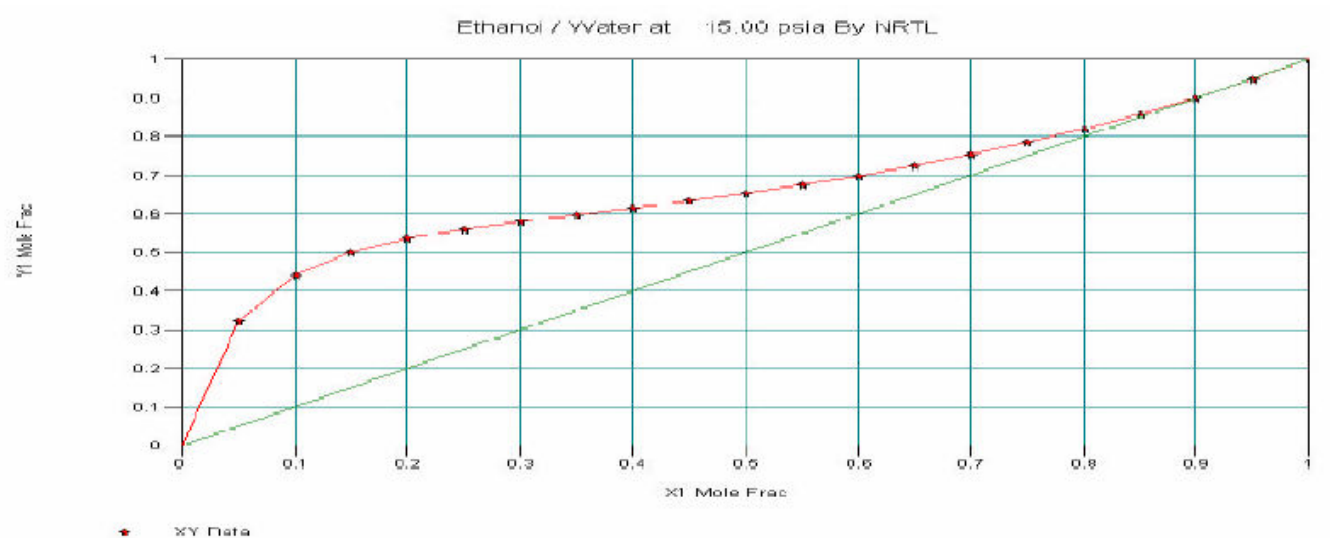

Figure 2. T-xy diagram for Ethanol-Water system generated by a process simulator using the NRTL model. 


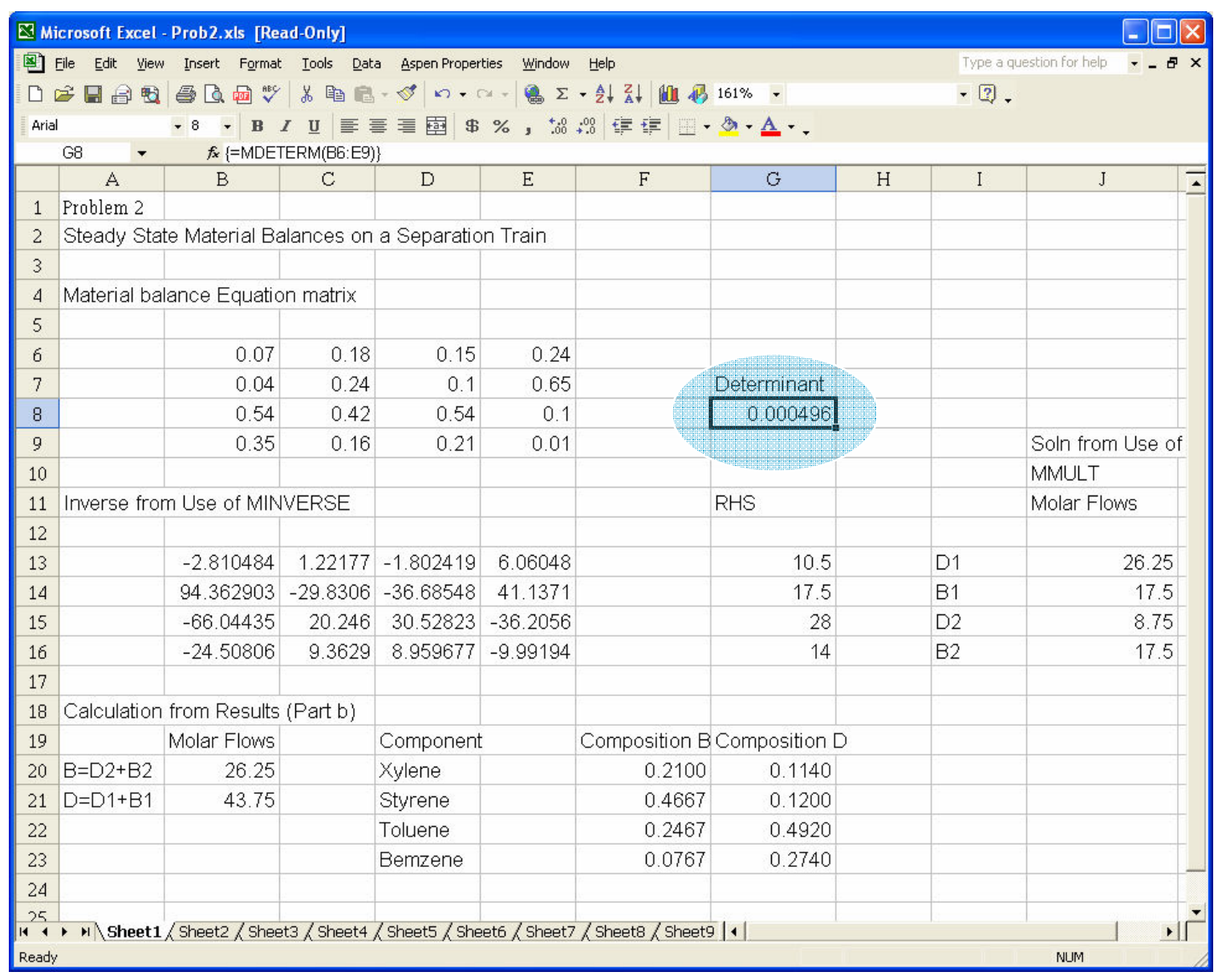

Figure 3. Solution of problem from Cutlip/Schacham indicating an ill-conditioned linear system. 


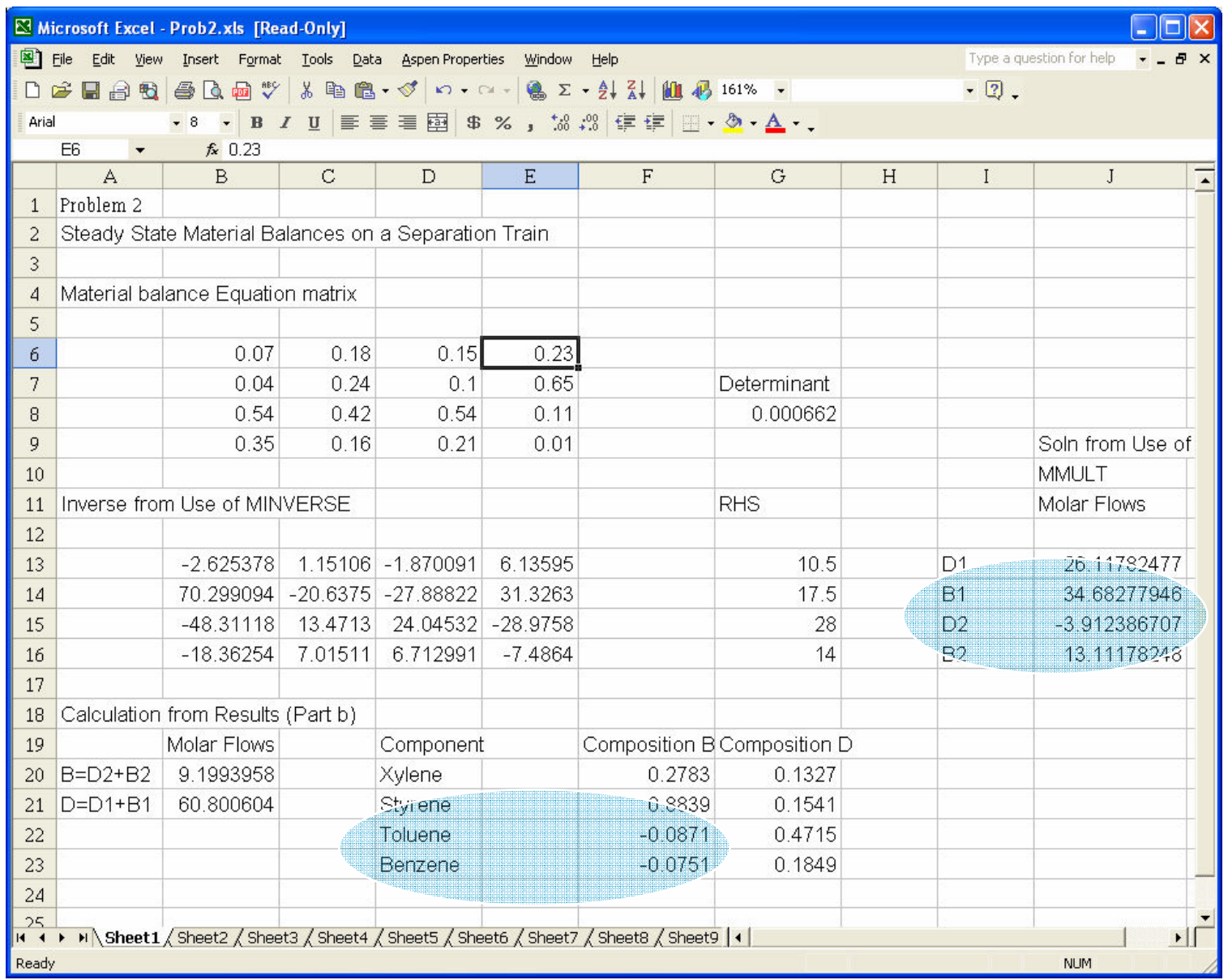

Figure 4. The resulting calculations when the specification of one product stream is slightly altered. Note that the compositions and flows reported are now unrealizable. 